\title{
ПОКОМПОНЕНТНАЯ ФУНКЦИЯ КОГЕРЕНТНОСТИ ВЗАИМОСВЯЗАННЫХ ПЕРИОДИЧЕСКИ НЕСТАЦИОНАРНЫХ СЛУЧАЙНЫХ ПРОЦЕССОВ
}

\author{
И. Н. ЯВОРСКИЙ ${ }^{1,2}$, Р. М. ЮЗЕФОВИЧ ${ }^{1}$, И. Й. МАЦЬКО ${ }^{1}$, З. ЗАКЖЕВСКИ ${ }^{2}$ \\ ${ }^{1}$ Физико-механический институт им. Г. В. Карпенко Национальной академии наук Украины, \\ Украина, Львов, 79601, ул. Научная 5 \\ ${ }^{2}$ Институт телекоммуникаичй технологически-естествоведческого университета, \\ Польша, Быдгощ, 85796, аллея проф. Калисскего 7
}

\begin{abstract}
Аннотация. Рассмотрена новая покомпонентная функция когерентности, которая определяется взаимоспектральными плотностями стационарных компонентов периодически нестационарных случайных сигналов - стационарно связанных случайных процессов, модулирующих их несущие гармоники. Свойства введенной функции когерентности конкретизированы для амплитудно- и фазомодулированных сигналов, получены ее графические частотные зависимости для заданных параметров сигналов. Показаны преимущества покомпонентной функции когерентности в сравнении с ранее введенной интегральной функцией когерентности. Приведен метод выделения стационарных модулирующих компонентов, который основан на частотном сдвиге и низкочастотной фильтрации. Проанализированы свойства выделяемых компонентов в случае амплитудных и фазовых модуляций.
\end{abstract}

Ключевые слова: периодически нестационарный случайный процесс; модулирующие стационарно связанные случайные процессы; линейные преобразования; амплитудно-модулированный сигнал; фазомодулированный сигнал

\section{ВСТУПЛЕНИЕ}

Важной задачей при анализе взаимосвязанности случайных сигналов является определение той частотной области, в которой проявляется зависимость вероятностных свойств одного из сигналов от таковых другого. Введеная при иследовании стационарных случайных сигналов функция когерентности $[1,2]$

$$
\gamma_{\xi \eta}(\omega)=\frac{\left|f_{\xi \eta}(\omega)\right|}{\left|f_{\xi}(\omega) f_{\eta}(\omega)\right|^{1 / 2}}
$$

где $f_{\xi \eta}(\omega)$ - взаимная спектральная плотность стационарно связанных сигналов $\xi(t)$ и $\eta(t), f_{\xi}(\omega)$ и $f_{\eta}(\omega)$ - их спектральные плотности мощности, дает возможность установить

DOI: $10.20535 / S 0021347017010046$

(с) И. Н. Яворский, Р. М. Юзефович, И. Й. Мацько, З. Закжевски, 2017 ту часть средней мощности сигнала $\eta(t)$, которая на частоте $\omega$ определяется мощностью сигнала $\xi(t)$.

Важным свойством функции когерентности (1) является то, что в случае, когда стационарные сигналы $\xi(t)$ и $\eta(t)$ являются результатом линейных преобразований одного и того же стационарного сигнала, она равняется 1. Это послужило основой для использования ее при исследовании одно- и многоканальных систем передачи информации, идентификации путей распространения сигналов, локализации их источников, выявлении нелинейных искажений и др. $[1,2]$. Однако спектральные плотности мощности $f_{\xi}(\omega)$ и $f_{\eta}(\omega)$, входящие в (1), определяют только спектральные составы сигналов, а взаимная спектральная плот- 


\section{БИБЛИОГРАФИЧЕСКИЙ СПИСОК}

1. Bendat J.S. Random Data: Analysis and Measurement Procedures / J. S. Bendat, A. G. Piersol. New York : John Wiley@, Sons, 2010._640 p.

2. Kay S. Modern Spectral Estimation: Theory and Application / S. Kay. — New Jersey : Prentise Hall, 1987. $-543 \mathrm{p}$.

3. Яворський I. М. Математичні моделі та аналіз стохастичних коливань / І. М. Яворський ; під заг. ред. 3. Т. Назарчука. — Львів : ФМІ НАНУ, 2013. — 804 с.

4. Яворський I. М. Взаємоз періодично корельовані випадкові процеси / I. М. Яворський, І. Б. Кравець, Р. М. Юзефович // Відбір і обробка інформації. - 2011. — № 34. - С. 69-77.

5. Функция когерентности взаимосвязанных периодически нестационарных случайных процессов / И. Н. Яворский, Р. М. Юзефович, И. Й. Мацько, 3. Закжевски // Известия вузов. Радиоэлектроника. - 2016. - T. 59, № 3. - C. 40-51. - DOI : 10.20535/S0021347016030043.

6. Gardner W. A. Eexploitation of spectral redundancy in cyclostationary signals / W. A. Gardner // IEEE SP Magazine (Signal Processing). - Apr. 1991. - Vol. 8, No. 2. - P. 14-36. - DOI : 10.1109/79.81007.

7. Cyclostationarity in Communications and Signal Processing // Ed. by W. A. Gardner. - New York : IEEE Press, 1994. $-504 \mathrm{p}$.

8. Hurd H. L. Periodically Correlated Random Sequences. Spectral Theory and Practice / H. L. Hurd, A. Miamee. - New Jersey : Wiley-Interscience, 2007. $-353 \mathrm{p}$

9. Napolitano A. Cyclostationarity: New trends and applications / A. Napolitano // Signal Processing. — Mar. 2016. - Vol. 120. - P. 385-408. — DOI : 10.1016/j.sigpro.2015.09.011.

10. ObuchowskiJ. Identification of cyclic components in presence of non-Gaussian noise application to crusher bearings damage detection / J. Obuchowski, A. Wylomanska, R. Zimroz // J. Vibroengineering. - 2015. - Vol. 17, No. 3. P. 1242-1252. - URL http://www.jve.lt/Vibro/JVE-2015-17-3/JVE0171505158 9.html.

11. ObuchowskiJ. The local maxima method for enhancement of time-frequency map and its application to local damage detection in rotating machines / J. Obuchowski, A. Wylomanska, R. Zimroz // Mechanical 
Systems and Signal Processing. — Jun. 2014. — Vol. 46, No. 2 - $-\quad$ P. 389-405. - DOI 10.1016/j.ymssp.2014.01.009.

12. Linear filtration methods for statistical analysis of periodically correlated random processes-Part II:
Harmonic series representation / I. Javorskyj, J. Leskow, I. Kravets, I. Isayev, E. Gajecka // Signal Processing. Nov. 2011. - Vol. 91, No. 11. - P. 2506-2519. - DOI : 10.1016/j.sigpro.2011.04.031. 